\title{
Ground Penetrating Radar in Pipeline River Crossing Design A Case Study from the Jungles of Ecuador
}

\author{
Jan C. Francké \\ 4389 Osler Street \\ Vancouver, B.C. \\ Canada \\ $+16047394044$
}

\begin{abstract}
A ground penetrating radar (GPR) survey was conducted to delineate sub-bottom geological strata for a pipeline river crossing project in Ecuador. The primary purpose of this investigation was to map a thick gravel layer underlying sands and silts to a total depth of over 40 metres. Despite significant depth requirements and logistical difficulties, radar data of excellent quality were acquired. This allowed the production of river crossing profiles which were believed to be of greater accuracy and detail than those generated by traditional geotechnical methods.
\end{abstract}

\section{INTRODUCTION}

Directionally-drilled pipeline river crossings in potentially problematic geological environments require a detailed and precise knowledge of subsurface features for effective design, bid and construction decisions. Geotechnical surveys involving boreholes, sometimes coupled with shallow seismic programmes, have been traditionally utilized for such investigations. With increasing frequency, ground penetrating radar (GPR) technology is being employed in the mapping of geological features beneath rivers for civil engineering applications. In combination with a fewer number of strategically placed boreholes, GPR commonly offers a more cost-effective and higher resolution view of the subsurface than conventional techniques, with little or no environmental impact. Delineating the distribution of sand, gravel and boulder horizons as well as profiling the bedrock surface and detecting fractures or fault zones are often possible using GPR.

This work presents a case study of a successful GPR survey conducted for Occidental Exploration and Production Company, on the Río Napo in Ecuador's Oriente jungle. This region of the kilometre-wide Napo had proved highly problematic during previous directional drill programmes due to thick gravel units, resulting in significant cost-overruns. Primary objectives of the radar survey included mapping the undulating sand, gravel, and bedrock interfaces parallel to the river channel, as well as producing accurate crossing profiles. Ground penetrating radar sections were then correlated to borehole information to provide a more detailed interpretation of the geophysical data.

'Current affiliation - Associated Mining Consultants Ltd., Vancouver, Canada. 


\section{PROGRAMME METHODOLOGY}

A Sensors and Software PulseEKKO ${ }^{\text {TM }}$ IV ground penetrating radar instrument was utilized to acquire subsurface geophysical information at the Río Napo crossing. Although sacrificing some profile resolution, $12.5 \mathrm{MHz}$ centre frequency antennas were selected for data production in order to provide maximum depth penetration.

GPR profiles were initially acquired both on the river bank and within the river channel along the north shore, for a distance of approximately 1,500 metres. This preliminary investigation was performed to assist in determining sites of suitable pipeline crossings, indicated by a rise in bedrock coupled with a thinner gravel unit. As a result of this survey, two potential alignments were highlighted for further investigation. Radar data were acquired across each of these alignments as well as at other locations both upstream and downstream for correlation purposes.

Data acquisition on the river portion of the survey was completed by mounting the radar instrumentation on a flat bottom fiberglass swamp boat. Due to anticipated depth penetration requirements, the $12.5 \mathrm{MHz}$ antennas were to be aligned perpendicular to the profiling direction, with an inter-antenna separation of twelve metres. This configuration was determined by initial field experimentation and represented a compromise between signal over-saturation and operational limitations.

Of consideration during river data acquisition utilizing $12.5 \mathrm{MHz}$ elements are their length, weight, and general fragility. The Río Napo represented numerous perils ranging from high waves, submerged logs, and sand banks, to aquatic predators who have been known to mistake antenna elements skimming the surface as viable prey. A method of gaining maximum antenna separation, while maintaining close control of their height above the water, was achieved by the use of two long wooden cantilevers manned by local labor (Figure 1). This design allowed the rapid extraction of each element from the water if necessary. It was however noted that site conditions $\left(40^{\circ} \mathrm{C}\right)$ allowed the eight-metre long, $20 \mathrm{~kg}$ antennas remarkable flexural compliancy.

In order to maximize surface coupling, which has been shown to be best achieved with antenna heights of less than 1/10th of the free-space wavelength (Smith, 1984), elements were maintained near the water surface. It was observed that increases in antenna elevation above the water substantially decreased the signal to noise ratio due to electromagnetic interference from the outboard boat engine. This EMI produced high-amplitude multiples throughout the

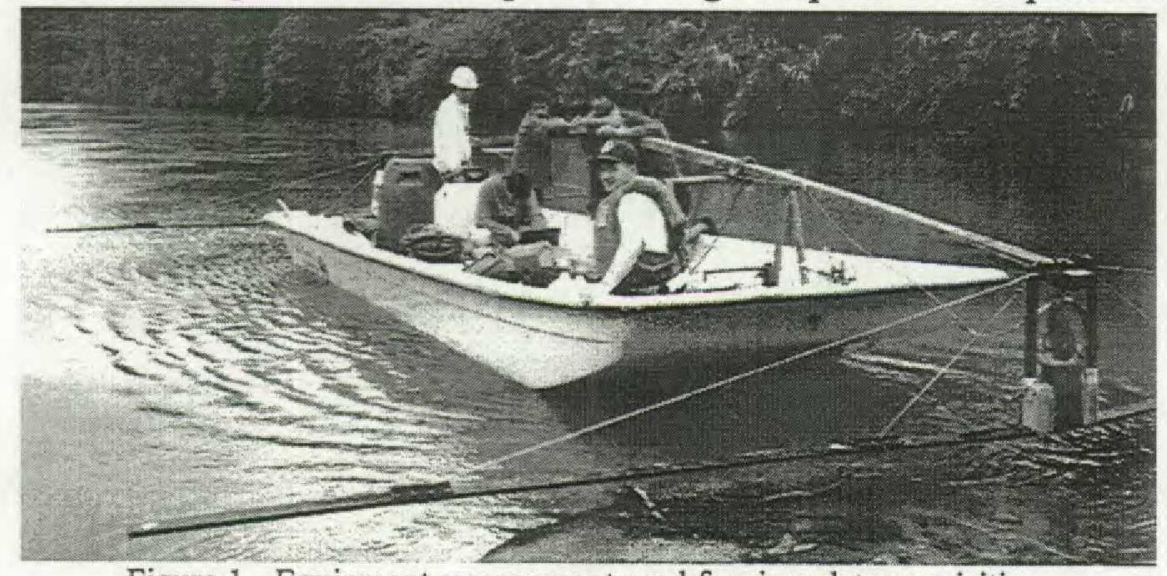

Figure 1 - Equipment arrangement used for river data acquisition 
data set which shifted in the time domain with changes in the engine's RPM. Efforts were made to maintain a constant engine speed, allowing the use of multiple suppression routines in subsequent data processing. Field experimentation indicated that data of diminished quality were recorded when the antenna elements were slightly submerged. This is due to the reduced effect of the air / water interface, resulting in a more omnidirectional emitted electric field pattern within the dielectric (Brewitt-Taylor et al, 1981).

Data were acquired in continuous mode at two second intervals. Accurate positioning control on the river portion of the survey was achieved by the use of a laser EDM equipped with multiple prisms on shore for triangulation. Data underwent subsequent spatial correction for inconsistencies in the boat's speed and heading. The use of a GPS system was discounted due to potentially inadequate equatorial satellite coverage as well as significant multipathing caused by shore vegetation.

\section{DISCUSSION OF RESULTS}

Depth penetration of radar data acquired on the banks of the river was inhibited by the thick, highly-conductive clay overburden. However, exemplary radar data were recorded within the river channel using low frequency antennas, despite a deep thalweg, heavy conductive sediment load, and significant operational difficulties. Aside from those caused by EMI from the boat engine, the radar data were relatively unaffected by multiples within the water. This is attributed to careful control of antenna heights as well as the low reflection coefficient at the river bottom / saturated sand layer interface.

Due to space limitations, two example radar profiles are presented. Figure 2 shows a 740 metre line acquired parallel to the north bank, approximately coincident to the thalweg. An interpretation is overlain these data, indicating bathymetry as well as the sand and gravel units. An interpreted bedrock high is indicated near position 450 on the profile. A similar bedrock feature was mapped 680 metres upstream from this location. The positioning of these features and the associated thin gravels were primary objectives of the GPR survey. Numerous radar profiles were acquired across the river at these two locations, with discernible reflected horizons at depths exceeding $1100 \mathrm{~ns}$. An example of an 840 metre river crossing profile is shown in Figure 3 with numerous subsurface horizons visible on the data. Accurate identification of substrate media was not possible due the low resolution of the antennas. Geophysical processing of the river data involved a combination of multiple suppression, frequency filtering, spectral balancing and deconvolution, and was data set specific.

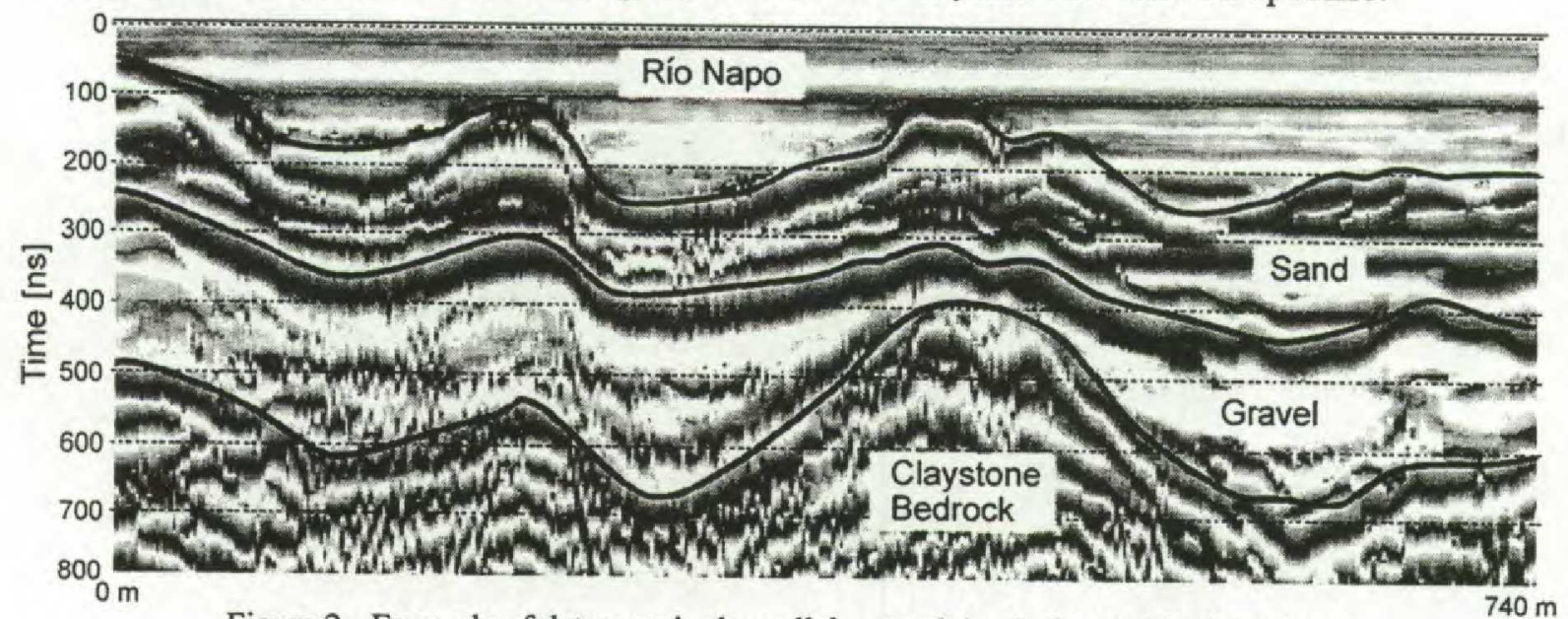

Figure 2 - Example of data acquired parallel to north bank showing bedrock high 


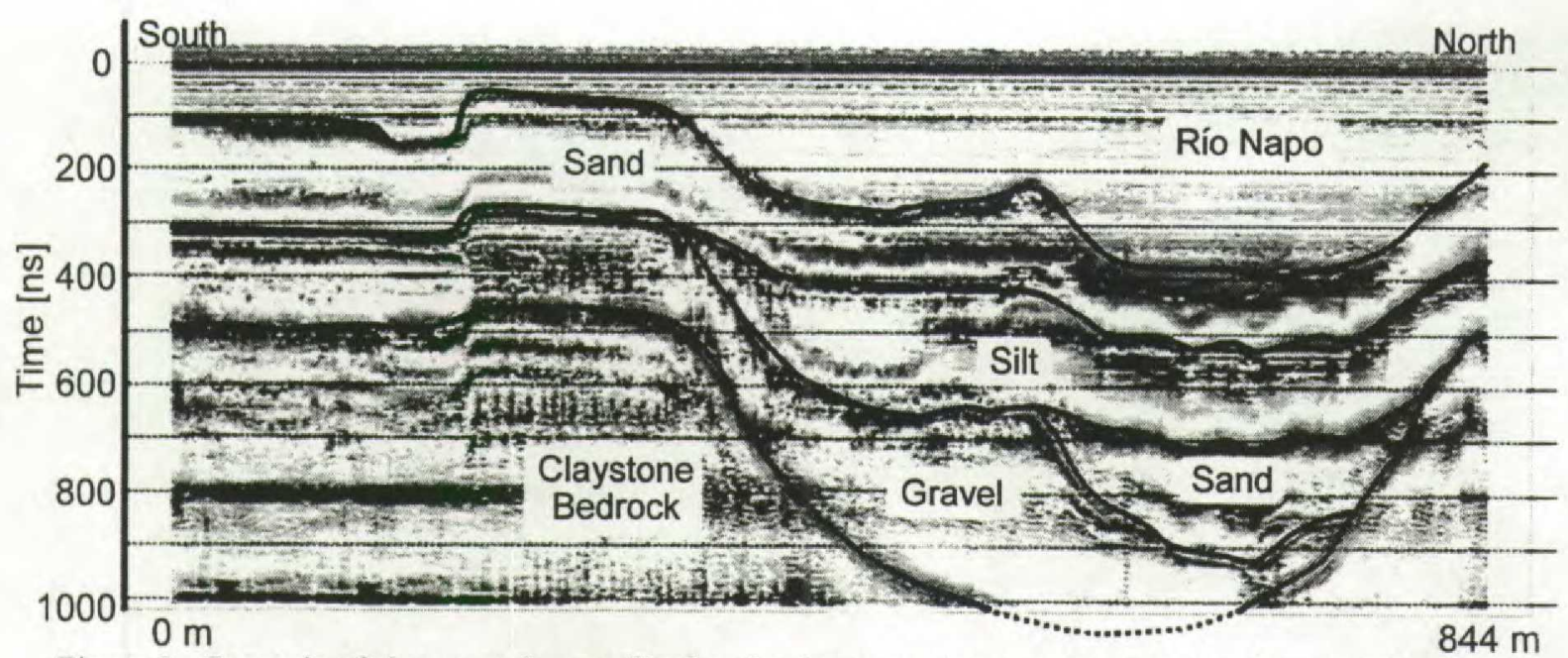

Figure 3 - Example of river crossing profile showing interpretation corroborated by subsequent boreholes

Based on the results of the ground penetrating radar investigation, a series of strategically placed boreholes provided additional information which enabled the precise identification of each detected horizon. The correlation of the GPR data to borehole information was excellent, allowing the production of accurate river crossing profiles which identified gravel, sand and silt horizons.

\section{CONCLUSION}

This survey has shown that GPR is a viable technique for investigation of near-surface sediments in an active river environment, with applicability to large-scale geotechnical and civil engineering projects. Within the Río Napo, sub-bottom horizons were mapped to depths exceeding 40 metres with excellent accuracy corroborated by subsequent boreholes. It is believed that the use of ground penetrating radar technology was crucial in the design of this pipeline project, resulting in the least expensive river crossing of its magnitude in the Oriente to date.

\section{ACKNOWLEDGMENTS}

Gratitude is extended to Occidental Exploration and Production Company of Quito, Ecuador, for the opportunity to perform this investigation and the permission to publish project information and GPR data. Appreciation is also expressed to Mr. Richard Ashton for his crucial assistance with project co-ordination, site data acquisition and interpretation.

\section{REFERENCES}

Brewitt-Taylor, C.R., Gunton, D.J., and Rees, H.D., 1981. Planar Antennas on a Dielectric Surface. Electronics Letters, vol. 17, No. 20, pp. 729-730.

Parker, R.P., and Roberts, B.J., 1996. Planificación del Cruce del Oleoducto Bajo El Río Napo Utilizando El Método de Perforación Horizontal. Proceedings of the X Congresso Latinoamericano de Perforación, Quito, Ecuador, October 21-24.

Smith, G.S., 1984. Directive Properties of Antennas for Transmission into a Material HalfSpace. IEEE Transactions on Antennas and Propagation, vol. AP-32, pp. 232-246. 